\title{
Enantioselective Synthesis of Allylboronates and Allylic Alcohols via Copper-Catalyzed 1,6-Boration
}

\author{
Yunfei Luo, Iain D. Roy, Amaël G. E. Madec, and Hon Wai Lam*
}

\begin{abstract}
Chiral secondary allylboronates are obtained in high enantioselectivities by the copper-catalyzed 1,6-boration of electron-deficient dienes with $B_{2}(\text { pin })_{2}$. The reactions proceed efficiently using catalyst loadings as low as 0.0049 mol\%. The allylboronates may be oxidized to the allylic alcohols, and can be used in stereoselective aldehyde allylborations. This process was applied to a concise synthesis of atorvastatin.
\end{abstract}

Enantioselective transition-metal-catalyzed reactions have transformed the way in which enantiomerically enriched chiral compounds can be prepared. However, the majority of industrial scale catalytic asymmetric processes developed to date employ precious second- or third-row transition metals that are costly and limited in availability. ${ }^{[1]}$ Moreover, the chiral ligands employed in these reactions are often expensive. Therefore, new enantioselective reactions that are catalyzed by earth-abundant metals, and that proceed efficiently at very low catalyst loadings to minimize the quantity of chiral ligand employed, are in high demand.

Given the ability of electron-deficient dienes to serve as effective substrates for various catalytic asymmetric 1,6addition reactions, ${ }^{[2,3]}$ we became interested in the enantioselective 1,6-boration of $\alpha, \beta, \gamma, \delta$-unsaturated carbonyl compounds as a potential method to prepare functionalized chiral allylboronates ${ }^{[4]}$ and allylic secondary alcohols, ${ }^{[5]}$ which are versatile building blocks for synthesis. Although enantioselective 1,4-borations of electron-deficient alkenes are well-established using chiral catalysts based upon copper, ${ }^{[6-8]}$ other metals, ${ }^{[9]}$ or by using organocatalysts, ${ }^{[10]}$ the enantioselective 1,6-boration of electron-deficient dienes

[*] Dr. Y. Luo, I. D. Roy, A. G. E. Madec, Prof. H. W. Lam EaStCHEM, School of Chemistry, University of Edinburgh Joseph Black Building, The King's Buildings, West Mains Road, Edinburgh EH9 3JJ (UK)

Dr. Y. Luo, A. G. E. Madec, Prof. H. W. Lam School of Chemistry, University of Nottingham University Park, Nottingham, NG7 2RD (UK) E-mail: hon.lam@nottingham.ac.uk Homepage: http://www.nottingham.ac.uk/ pczhl

[**] We thank the ERC (Starting Grant No. 258580), the EPSRC (Leadership Fellowship to H.W.L.), Pfizer, AstraZeneca, and the University of Edinburgh for support. We thank Xiaoming Yang of Shanghai Chiral Chemistry Co., Ltd. for providing starting materials and NMR data for atorvastatin (12). We are grateful to Dr. Gary S. Nichol (University of Edinburgh) for $X$-ray crystallography, and the EPSRC National Mass Spectrometry Facility for high-resolution mass spectra. We thank Dr. Ai-Lan Lee at Heriot-Watt University for the use of a polarimeter.

Supporting information for this article is available on the WWW under http://www.angewandte.org
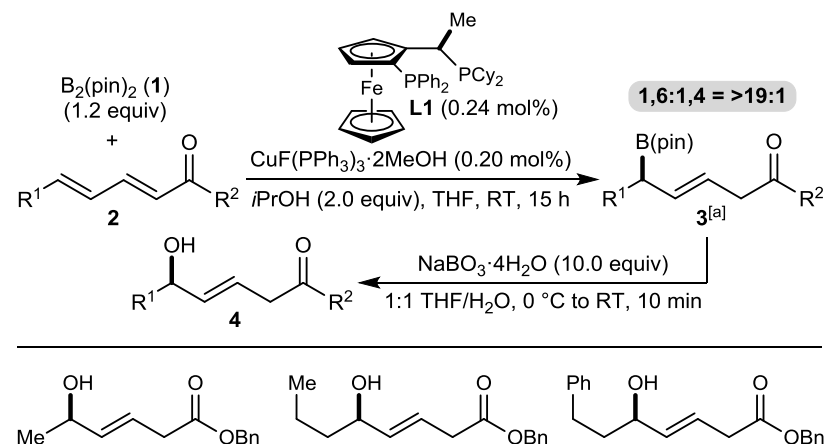

4a $91 \%, 95 \%$ ee $\quad$ 4b $86 \%, 95 \%$ ee $\quad$ 4c $86 \%, 96 \%$ ee<smiles>O=C(C/C=C/C(O)CCN1CCOCC1)OCc1ccccc1</smiles><smiles>O=C(CC=CC(O)CCCCCl)Cc1ccccc1</smiles><smiles>CC(C)COCC(O)/C=C/CC(=O)OCc1ccccc1</smiles><smiles>CCOC(=O)C/C=C/C(O)COC(C)C</smiles>

4g $75 \%, 95 \%$ ee<smiles>CCOC(=O)C/C=C/C(O)CCNC(=O)c1ccccc1</smiles>
4h $75 \%, 95 \%$ ee<smiles>CCCCCCCCC(=O)OC(C)C</smiles><smiles>CC(O)C=CCC(=O)c1ccccc1</smiles><smiles>COc1ccc(C(=O)C/C=C/C(C)(C)C)cc1</smiles><smiles>CC(O)C=CCC(=O)c1ccc(Cl)cc1</smiles><smiles>CC(=O)CC=CC(O)COCC(C)C</smiles>

Scheme 1. Scope of enantioselective 1,6-boration-oxidation. Reactions were conducted with $0.50 \mathrm{mmol}$ of 2 . Cited yields are of isolated material. Enantiomeric excesses were determined by HPLC analysis on a chiral stationary phase. [a] Pure allylboronate $3 a\left(R^{1}=\right.$ Me, $R^{2}=O B n$ ) was isolated in $80 \%$ yield and $96 \%$ ee without performing the oxidation. [b] Enantiomeric excess determined on the corresponding benzoate ester. [c] Oxidation was performed using 5.0 equiv of $\mathrm{NaBO}_{3} \cdot 4 \mathrm{H}_{2} \mathrm{O}$. [d] Isolated along with $8 \%$ of the $E$-conjugated enone. [e] Isolated along with $6 \%$ of the $E$-conjugated enone.

is not well-developed. Progress has been made in related processes such as enantioselective copper-catalyzed monoboration $^{[4 \mathrm{~h}]}$ and platinum-catalyzed 1,4-diboration of 1,3-dienes. ${ }^{[11]}$ Kobayashi and co-workers also recently reported four examples of enantioselective $\mathrm{Cu}$ (II)-catalyzed 1,6-borations of $\alpha, \beta, \gamma, \delta$-unsaturated cyclic ketones with 33$89 \%$ ee, using a $5 \mathrm{~mol} \%$ catalyst loading ${ }^{[2 \mathrm{j}]}$ However, these substrates were disubstituted at the $\beta$-position, and acyclic $\alpha, \beta, \gamma, \delta$-unsaturated carbonyls lacking an additional group at the $\beta$-carbon underwent exclusive 1,4-boration.

Herein, we describe highly enantioselective coppercatalyzed 1,6-borations of acyclic $\alpha, \beta, \gamma, \delta$-unsaturated esters 
and ketones. High selectivities for 1,6-boration over 1,4boration are achieved without a "blocking" substituent at the $\beta$-carbon. In addition, the chiral copper complex employed exhibits high stability, allowing the reactions to proceed effectively at catalyst loadings as low as $0.0049 \mathrm{~mol} \%$. Application of this method to the synthesis of the cholesterollowering drug atorvastatin is also described.

This study began with a search for an effective method for the enantioselective copper-catalyzed 1,6-addition of bis(pinacoloto)diboron (1, 1.2 equiv) to benzyl sorbate (2a) (see the Supporting Information for full details). The best results were obtained using $\left[\mathrm{CuF}\left(\mathrm{PPh}_{3}\right)_{3} \cdot 2 \mathrm{MeOH}\right]$ and the Josiphos ligand $\mathbf{L 1}^{[6 \mathrm{c}, \mathrm{d}, 8 \mathrm{c}, \mathrm{f}]}$ in THF at room temperature, in the presence of $i \operatorname{PrOH}$ (2.0 equiv) as a protic additive. ${ }^{[6 \mathrm{c}, 8 \mathrm{f}]}$ The 1,6-boration of 2 a proceeded smoothly on a $0.50 \mathrm{mmol}$ scale using only $0.20 \mathrm{~mol} \%$ of the copper complex $\left[\mathrm{CuF}\left(\mathrm{PPh}_{3}\right)_{3} \cdot 2 \mathrm{MeOH} / \mathbf{L 1}\right]$ (Scheme 1). After the reaction was complete, filtration of the mixture through a short plug of silica using EtOAc as the eluent and removal of the solvent provided the $E$-allylboronate $\mathbf{3 a}$, accompanied by $\mathrm{HOB}$ (pin). Oxidation of this mixture with $\mathrm{NaBO}_{3} \cdot 4 \mathrm{H}_{2} \mathrm{O}^{[12]}$ then gave the allylic alcohol 4a in 91\% isolated yield over the two steps and in $95 \% e e .^{[13]}$ Alternatively, pure allylboronate 3a was isolated in $80 \%$ yield and $96 \%$ ee by using $5 \% \mathrm{Et}_{2} \mathrm{O} /$ hexane in the filtration of the 1,6-boration reaction mixture. ${ }^{[14]} \mathrm{A}$ range of other $\alpha, \beta, \gamma, \delta$-unsaturated benzyl esters also underwent enantioselective 1,6-boration-oxidation to provide allylic alcohols $\mathbf{4 a - 4 f}$ in $70-92 \%$ yield, high regioselectivities (>19:1 ratio of 1,6-:1,4-addition) and high enantioselectivities $(95-96 \%$ ee $)$. In addition to benzyl sorbate (2a), substrates containing other linear alkyl groups at the $\delta$-position were effective (4b and $\mathbf{4 c}$ ). The process is compatible with nitrogen-containing substituents (4d and 4h), an alkyl chloride (4e), and silyl ethers (4f and $\mathbf{4 g}$ ). Substrates containing ethyl esters $(\mathbf{4 g}$ and $\mathbf{4 h})$ or $t$-butyl esters (4i) were also tolerated. However, a substrate containing a phenyl group at the $\delta$-position provided a complex mixture of unidentified products. The process is not limited to esters as the activating group; $\alpha, \beta, \gamma, \delta$-unsaturated aryl and alkyl ketones were also effective $(\mathbf{4} \mathbf{j}-\mathbf{4 m})$.

The selectivity for 1,6-boration over 1,4-boration is sensitive to steric effects, as shown by the boration-oxidation of $\mathbf{2 n}$, which contains a $\delta$-cyclopropyl group. This reaction gave the 1,4-adduct $\mathbf{5 a}$ as the major product in $49 \%$ yield and
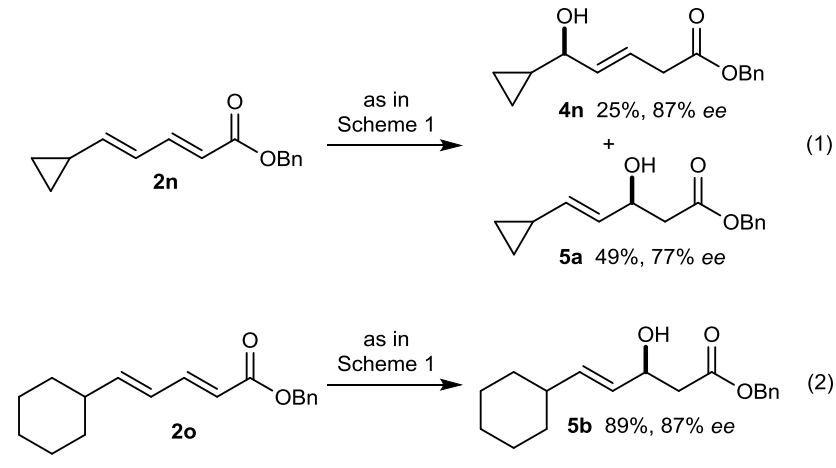

$77 \%$ ee, while the 1,6-adduct $4 \mathbf{n}$ was isolated in $25 \%$ yield and $87 \%$ ee [Eq. (1)]. Increasing the size of the $\delta$-substituent further led to exclusive 1,4-boration, as shown by the cyclohexyl-substituted substrate 20 which gave the $\beta$ hydroxyester $\mathbf{5 b}$ only, in $89 \%$ yield and $87 \%$ ee [Eq. (2)].The sense of enantioinduction in these reactions was determined by X-ray crystallography of potassium allyltrifluoroborate $\mathbf{6}$, which was obtained by 1,6-boration of $\mathbf{2 i}$ followed by immediate treatment of the resulting allylboronate $\mathbf{3 i}$ with $\mathrm{KF}$ and L-(+)-tartaric acid according to procedure of Lennox and Lloyd-Jones $^{[15]}$ (Scheme 2). ${ }^{[16]}$

$$
\begin{aligned}
& \overbrace{\mathbf{2} \mathbf{i}}^{\mathrm{O}_{\mathrm{O} t-\mathrm{Bu}}} \underset{\mathrm{as} \text { in Scheme 1 }}{\text { without oxidation }} \\
& \overbrace{\substack{6 \% \% \text { over } 2 \text { steps } \\
\text { (X-ray) }}}^{\mathrm{O}_{3} \mathrm{Bu}} \underset{\substack{\mathrm{MeCN} / \mathrm{MeOH} / \mathrm{THF} / \mathrm{H}_{2} \mathrm{O} \\
\mathrm{RT}, 10 \mathrm{~min}}}{\substack{\mathrm{KF}(4.0 \text { equiv) } \\
\text { L-(+)-tartaric acid (2.05 equiv) }}}
\end{aligned}
$$

Scheme 2. Conversion of $2 \mathrm{i}$ into the allyltrifluoroborate 6 .

Next, larger scale 1,6-borations were conducted to assess whether the catalyst loading could be decreased. ${ }^{[17]}$ A 40.4 mmol scale 1,6-boration of $\mathbf{2 a}$ with 1.06 equiv of $\mathrm{B}_{2}(\text { pin })_{2}(\mathbf{1})$, $0.0049 \mathrm{~mol} \%$ of $\mathrm{CuF}\left(\mathrm{PPh}_{3}\right)_{3} \cdot 2 \mathrm{MeOH}$ and $0.0074 \mathrm{~mol} \%$ of L1 was complete in $30 \mathrm{~h}$, providing 3a as an 11:1 mixture 1,6-:1,4-boration isomers (Scheme 3). Oxidation of 3a then gave $4 \mathbf{a}$ in $80 \%$ yield and $95 \%$ ee over the two steps. Notably, in this experiment, only $1.9 \mathrm{mg}$ of the chiral ligand $\mathbf{L 5}$ was required to prepare $7.10 \mathrm{~g}$ of $\mathbf{4 a} .^{[17]}$
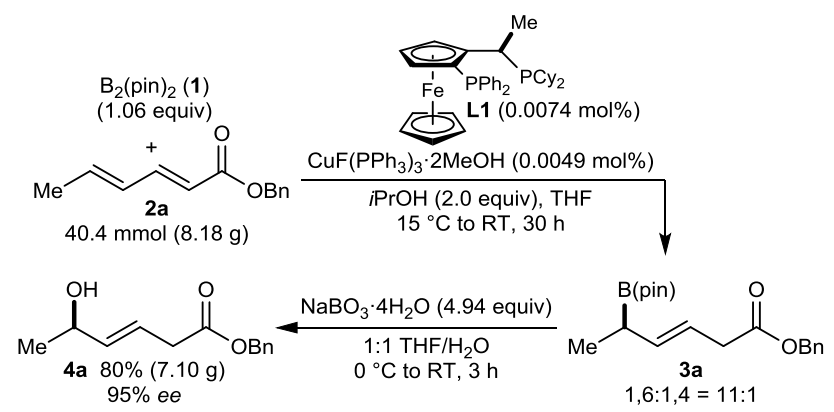

Scheme 3. Larger scale 1,6-boration-oxidation of 2a.

In addition to oxidation to allylic alcohols, the allylboronates resulting from 1,6-boration can be employed in stereoselective carbonyl allylborations. For example, treatment of $\mathbf{3 a}$ with benzaldehyde in the presence of $\mathrm{BF}_{3} \cdot \mathrm{OEt}_{2}$ provided homoallylic alcohol 7 in $77 \%$ yield as a 23:1 inseparable mixture of $E / Z$ isomers, and in $93 \%$ ee for the $E$-isomer [Eq. (3)]. ${ }^{[18]}$

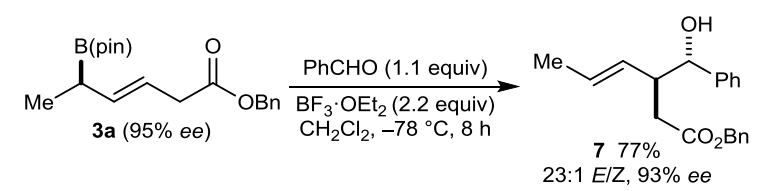

As a further demonstration of its utility, the enantioselective 1,6-boration was applied in a concise synthesis of atorvastatin (13), a well-known inhibitor of 3hydroxy-3-methylglutaryl coenzyme A reductase and the active ingredient in Lipitor, currently the best-selling pharmaceutical in history. ${ }^{[1-21]}$ The synthesis began with 

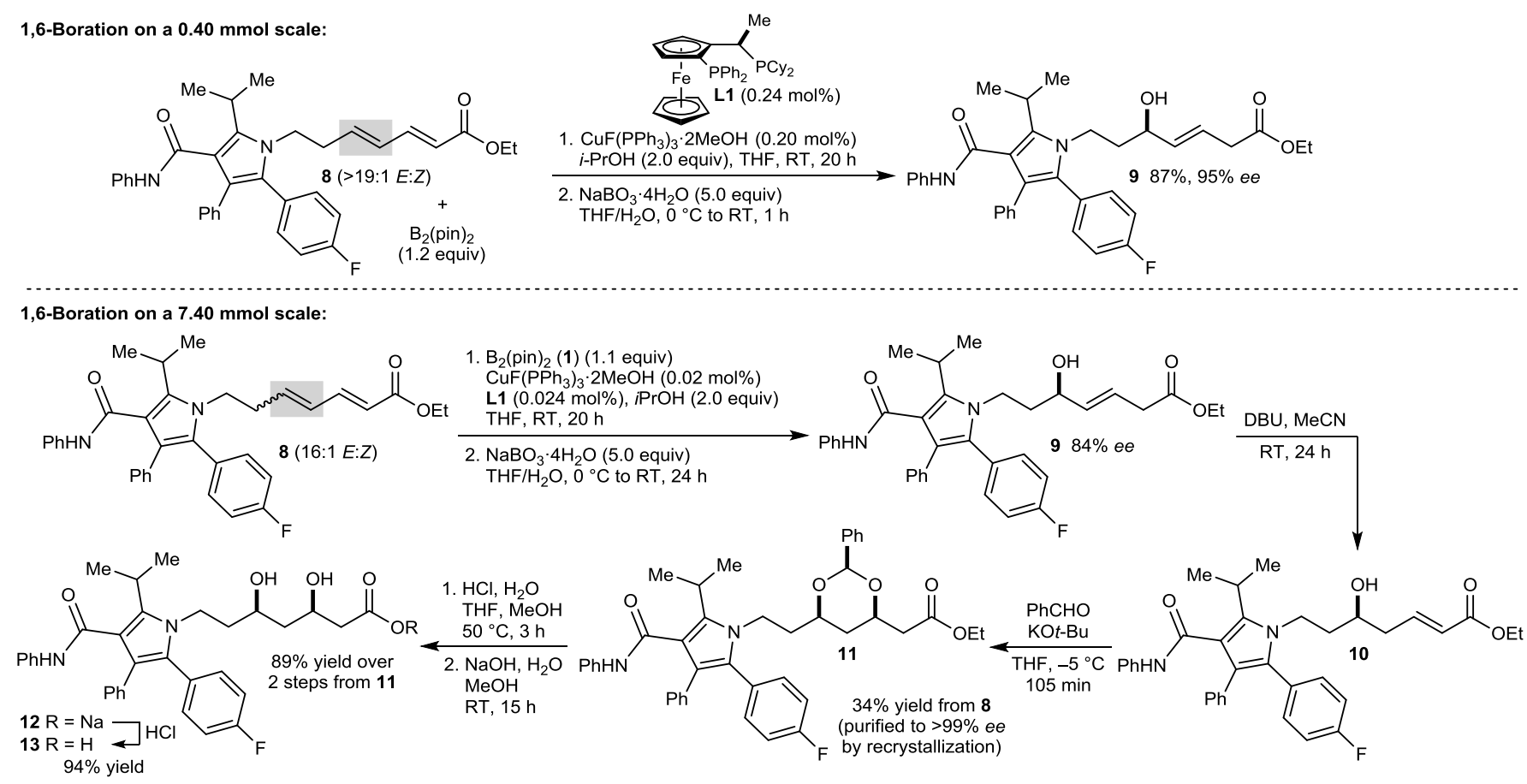

Scheme 4. Enantioselective synthesis of atorvastatin (13).

the preparation of diene $\mathbf{8}^{[22]}$ Enantioselective 1,6-borationoxidation of geometrically pure 8 (obtained in $39 \%$ overall yield from commercial starting materials) on a $0.40 \mathrm{~mol}$ scale gave the allylic alcohol 9 in $87 \%$ yield and 95\% ee (Scheme 4 , top). However, multiple recrystallizations were required to obtain $\mathbf{8}$ in geometrically pure form, and for reasons of practicality as well as overall yield, it was preferable to use a 16:1 $E: Z$ mixture of 8 (obtained in $60 \%$ overall yield from commercial starting materials) in the synthesis of atorvastatin (Scheme 4, bottom). ${ }^{[22]}$

Enantioselective 1,6-boration of this 16:1 E:Z mixture of 8 on a $7.40 \mathrm{mmol}$ scale proceeded smoothly using only 0.02 mol\% of the $\mathrm{Cu}(\mathrm{I})-\mathrm{J}$ osiphos complex, and oxidation of the resulting allylboronate with $\mathrm{NaBO}_{3} \cdot 4 \mathrm{H}_{2} \mathrm{O}$ provided the allylic alcohol 9 in $84 \%$ ee (Scheme 4 , bottom). The lower enantioselectivity of this reaction is due to the presence $(\sim 6 \%)$ of the minor $2 E, 4 Z$-isomer of diene $\mathbf{8}^{[23]}$ Without purification, 9 was isomerized to the conjugated ester $\mathbf{1 0}$ with catalytic $\mathrm{DBU}$ in $\mathrm{MeCN}$ at room temperature. The crude $\alpha, \beta-$ unsaturated ester $\mathbf{1 0}$ was then reacted with benzaldehyde and $\mathrm{KO} t \mathrm{Bu}$ according to the method of Evans and co-workers ${ }^{[24]}$ which gave the benzylidene acetal-protected syn-1,3-diol 11 with high diastereoselectivity $(>19: 1 \mathrm{dr}) \cdot{ }^{[21 \mathrm{c}]}$ Recrystallization of 11 from $i \mathrm{PrOH} /$ hexane led to selective crystallization of the racemate, which enabled isolation of an enantioenriched sample of 11 ( $>99 \%$ ee $)$ in 34\% yield over the four steps from 8 after concentration of the mother liquor. Deprotection of the acetal of $\mathbf{1 1}$ with $\mathrm{HCl}$ was followed by basic hydrolysis of the ester with $\mathrm{NaOH}$ to give the sodium salt $\mathbf{1 2}$ of atorvastatin (13) in $89 \%$ yield, which was converted into atorvastatin (13) itself in $94 \%$ yield by acidification

In conclusion, we have reported highly enantioselective copper-catalyzed 1,6-borations of $\alpha, \beta, \gamma, \delta$-unsaturated carbonyl compounds with bis(pinacoloto)diboron (1). For the first time, high selectivities for 1,6-boration over 1,4-boration are achieved without a "blocking" substituent at the $\beta$-carbon.
The reactions proceed at ambient temperature and are promoted by a $\mathrm{Cu}(\mathrm{I})-\mathrm{Josiphos}$ complex at catalyst loadings as low as $0.0049 \mathrm{~mol} \%$ to provide chiral allylboronates en route to chiral secondary allylic alcohols. Application of this process on a $40.4 \mathrm{mmol}$ scale has been demonstrated. The allylboronates may also be employed in highly stereoselective allylborations of aldehydes. Finally, the utility of this methodology was demonstrated by a concise synthesis of atorvastatin (13), the well-known cholesterol-lowering drug. Efforts to understand the origin of the selectivity for 1,6-boration over 1,4-boration, which is currently unclear, along with the development of other catalytic enantioselective 1,6-additions, are topics for future study in our laboratory.

\section{Published online on ((will be filled in by the editorial staff))}

Keywords: 1,6-addition · asymmetric catalysis · boron · copper . enantioselectivity

[1] H.-U. Blaser, H.-J. Federsel, Editors, Asymmetric Catalysis On Industrial Scale: Challenges, Approaches, And Solutions, 2nd Edition, Wiley-VCH Verlag GmbH \& Co. KGaA, 2010.

[2] Metal-catalyzed enantioselective 1,6-additions: a) E. Fillion, A. Wilsily, E. T. Liao, Tetrahedron: Asymmetry 2006, 17, 2957-2959. b) T. den Hartog, S. R. Harutyunyan, D. Font, A. J. Minnaard, B. L. Feringa, Angew. Chem., Int. Ed. 2008, 47, 398-401. c) H. Hénon, M. Mauduit, A. Alexakis, Angew. Chem., Int. Ed. 2008, 47, 9122-9124. d) K.-s. Lee, A. H. Hoveyda, J. Am. Chem. Soc. 2010, 132, 2898-2900. e) K.-s. Lee, H. Wu, F. Haeffner, A. H. Hoveyda, Organometallics 2012, 31, 7823-7826. f) T. Hayashi, S. Yamamoto, N. Tokunaga, Angew. Chem., Int. Ed. 2005, 44, 42244227. g) T. Nishimura, Y. Yasuhara, T. Sawano, T. Hayashi, $J$. Am. Chem. Soc. 2010, 132, 7872-7873. h) T. Nishimura, A. Noishiki, T. Hayashi, Chem. Commun. 2012, 48, 973-975. i) T. Sawano, A. Ashouri, T. Nishimura, T. Hayashi, J. Am. Chem. Soc. 2012, 134, 18936-18939. j) T. Kitanosono, P. Xu, S. Kobayashi, Chem. Commun. 2013, 49, 8184-8186. k) J. Lu, J. Ye, W.-L. Duan, Chem. Commun. 2014, 50, 698-700. 
[3] Organocatalytic enantioselective 1,6-additions: a) L. Bernardi, J López-Cantarero, B. Niess, K. A. Jørgensen, J. Am. Chem. Soc. 2007, 129, 5772-5778. b) J. J. Murphy, A. Quintard, P. McArdle, A. Alexakis, J. C. Stephens, Angew. Chem., Int. Ed. 2011, 50, 5095-5098. c) X. Tian, Y. Liu, P. Melchiorre, Angew. Chem., Int Ed. 2012, 51, 6439-6442. d) D. Uraguchi, K. Yoshioka, Y. Ueki, T. Ooi, J. Am. Chem. Soc. 2012, 134, 19370-19373. e) L. Dell'Amico, Ł. Albrecht, T. Naicker, P. H. Poulsen, K. A. Jørgensen, J. Am. Chem. Soc. 2013, 135, 8063-8070. f) M. Silvi, I. Chatterjee, Y. Liu, P. Melchiorre, Angew. Chem., Int. Ed. 2013, 52, 10780-10783.

[4] For selected examples of the preparation of enantiomerically enriched chiral allylboron compounds, see: a) J. Pietruszka, N. Schöne, Angew. Chem., Int. Ed. 2003, 42, 5638-5641. b) H. Ito, C. Kawakami, M. Sawamura, J. Am. Chem. Soc. 2005, 127, 1603416035. c) F. Peng, D. G. Hall, Tetrahedron Lett. 2007, 48, 33053309. d) L. Carosi, D. G. Hall, Angew. Chem., Int. Ed. 2007, 46, 5913-5915. e) H. Ito, S. Ito, Y. Sasaki, K. Matsuura, M Sawamura, J. Am. Chem. Soc. 2007, 129, 14856-14857. f) H. Ito, T. Okura, K. Matsuura, M. Sawamura, Angew. Chem., Int. Ed. 2010, 49, 560-563. g) H. Ito, S. Kunii, M. Sawamura, Nature Chem. 2010, 2, 972-976. h) Y. Sasaki, C. Zhong, M. Sawamura, H. Ito, J. Am. Chem. Soc. 2010, 132, 1226-1227. i) M. Althaus, A. Mahmood, J. R. Suárez, S. P. Thomas, V. K. Aggarwal, J. Am. Chem. Soc. 2010, 132, 4025-4028. j) M. Chen, D. H. Ess, W. R. Roush, J. Am. Chem. Soc. 2010, 132, 7881-7883. k) J. C. H. Lee, R. McDonald, D. G. Hall, Nature Chem. 2011, 3, 894-899. 1) M. Chen, W. R. Roush, J. Am. Chem. Soc. 2011, 133, 5744-5747. m) L. T. Kliman, S. N. Mlynarski, G. E. Ferris, J. P. Morken, Angew. Chem., Int. Ed. 2012, 51, 521-524. n) A. P. Pulis, V. K. Aggarwal, J. Am. Chem. Soc. 2012, 134, 7570-7574. o) G. E. Ferris, K. Hong, I. A. Roundtree, J. P. Morken, J. Am. Chem. Soc. 2013, 135, 2501-2504.

[5] A. Lumbroso, M. L. Cooke, B. Breit, Angew. Chem., Int. Ed. 2013, 52, 1890-1932.

[6] Seminal references: a) K. Takahashi, T. Ishiyama, N. Miyaura, Chem. Lett. 2000, 29, 982-983. b) H. Ito, H. Yamanaka, J.-i. Tateiwa, A. Hosomi, Tetrahedron Lett. 2000, 41, 6821-6825. c) S. Mun, J.-E. Lee, J. Yun, Org. Lett. 2006, 8, 4887-4889. d) J.-E. Lee, J. Yun, Angew. Chem., Int. Ed. 2008, 47, 145-147. e) V. Lillo, A. Prieto, A. Bonet, M. M. Díaz-Requejo, J. s. Ramírez, P. J. Pérez, E. Fernández, Organometallics 2008, 28, 659-662.

[7] Reviews: a) E. Hartmann, D. J. Vyas, M. Oestreich, Chem. Commun. 2011, 47, 7917-7932. b) A. D. J. Calow, A. Whiting, Org. Biomol. Chem. 2012, 10, 5485-5497.

[8] For selected recent examples, see ref: $4 \mathrm{k}$ and: a) J. M. O'Brien, K.-s. Lee, A. H. Hoveyda, J. Am. Chem. Soc. 2010, 132, 1063010633. b) A. L. Moure, R. Gomez Arrayas, J. C. Carretero, Chem. Commun. 2011, 47, 6701-6703. c) E. Hartmann, M. Oestreich, Org. Lett. 2012, 14, 2406-2409. d) L. Zhao, Y. Ma, W. Duan, F. He, J. Chen, C. Song, Org. Lett. 2012, 14, 5780-5783. e) C. Sole, A. Bonet, A. H. M. de Vries, J. G. de Vries, L. Lefort, H. Gulyás, E. Fernández, Organometallics 2012, 31, 7855-7861. f) A. R. Burns, J. S. Gonzalez, H. W. Lam, Angew. Chem., Int. Ed. 2012, 51,10827-10831. g) A. D. J. Calow, A. S. Batsanov, E. Fernández, C. Solé, A. Whiting, Chem. Commun. 2012, 48, 11401-11403. h) S. Kobayashi, P. Xu, T. Endo, M. Ueno, T. Kitanosono, Angew. Chem., Int. Ed. 2012, 51, 12763-12766.

[9] a) T. Shiomi, T. Adachi, K. Toribatake, L. Zhou, H. Nishiyama, Chem. Commun. 2009, 5987-5989. b) V. Lillo, M. J. Geier, S. A. Westcott, E. Fernández, Org. Biomol. Chem. 2009, 7, 4674-4676. c) K. Toribatake, L. Zhou, A. Tsuruta, H. Nishiyama, Tetrahedron 2013, 69, 3551-3560.

[10] a) A. Bonet, H. Gulyás, E. Fernández, Angew. Chem., Int. Ed. 2010, 49, 5130-5134. b) I. Ibrahem, P. Breistein, A. Cordova, Chem. Eur. J. 2012, 18, 5175-5179. c) H. Wu, S. Radomkit, J. M. O'Brien, A. H. Hoveyda, J. Am. Chem. Soc. 2012, 134, 8277 8285.

[11] a) H. E. Burks, L. T. Kliman, J. P. Morken, J. Am. Chem. Soc. 2009, 131, 9134-9135. b) C. H. Schuster, B. Li, J. P. Morken,
Angew. Chem., Int. Ed. 2011, 50, 7906-7909. c) K. Hong, J. P. Morken, J. Org. Chem. 2011, 76, 9102-9108.

[12] C. N. Farthing, S. P. Marsden, Tetrahedron Lett. 2000, 41, 42354238.

[13] The absolute configurations of the products of this study were assigned by analogy with the allyltrifluoroborate $\mathbf{6}$, which was determined by X-ray crystallography (see the Supporting Information).

[14] The lower yield of 3a compared with that of $\mathbf{4 a}$ obtained in the two-step procedure is due to decomposition of $\mathbf{3 a}$ on silica during the longer duration of the filtration.

[15] A. J. J. Lennox, G. C. Lloyd-Jones, Angew. Chem., Int. Ed. 2012, 51, 9385-9388.

[16] CCDC 959663 (compound 6) contains the supplementary crystallographic data for this paper. These data can be obtained free of charge from The Cambridge Crystallographic Data Centre via www.ccdc.cam.ac.uk/data_request/cif.

[17] A $25.0 \mathrm{mmol}$ scale 1,6-boration of 2a with a $0.02 \mathrm{~mol} \%$ catalyst loading was complete in $15 \mathrm{~h}$, and provided $\mathbf{4 a}$ in $92 \%$ yield and 94\% ee after oxidation of 3a (see Supporting Information for full details).

[18] For $\mathrm{BF}_{3} \cdot \mathrm{OEt}_{2}$-promoted, $E$-selective allylborations of aldehydes with chiral secondary $E$-allylboronate esters, see Ref. [4e] and: a) F. Peng, D. G. Hall, J. Am. Chem. Soc. 2007, 129, 3070-3071. b) M. Chen, W. R. Roush, Org. Lett. 2010, 12, 2706-2709.

[19] B. D. Roth, C. J. Blankley, A. W. Chucholowski, E. Ferguson, M. L. Hoefle, D. F. Ortwine, R. S. Newton, C. S. Sekerke, D. R. Sliskovic, M. Wilson, J. Med. Chem. 1991, 34, 357-366.

[20] Reviews: a) B. D. Roth, in Progress in Medicinal Chemistry, Vol. 40 (Eds.: F. D. King, A. W. Oxford, A. B. Reitz, S. L. Dax), 2002, pp. 1-22. b) J. J. Li, D. S. Johnson, D. R. Sliskovic, B. D. Roth, in Contemporary Drug Synthesis, John Wiley \& Sons, Inc., 2004, pp. 113-124. c) Z. Casar, Curr. Org. Chem. 2010, 14, 816-845.

[21] Selected recent syntheses of atorvastatin: a) Y. Kawato, M. Iwata, R. Yazaki, N. Kumagai, M. Shibasaki, Tetrahedron 2011, 67, 6539-6546. b) L. Hu, F. Xiong, X. Chen, W. Chen, Q. He, F. Chen, Tetrahedron: Asymmetry 2013, 24, 207-211. c) Y. Kawato, S. Chaudhary, N. Kumagai, M. Shibasaki Chem. Eur. J. 2013, 19, 3802-3806.

[22] See the Supporting Information for details of the synthesis of $\mathbf{8}$.

[23] The $2 E, 4 Z-\alpha, \beta, \gamma, \delta$-unsaturated ester 14 underwent 1,6-borationoxidation to give ent-4g in only $42 \%$ ee, with the opposite absolute configuration to that depicted in Scheme 1.

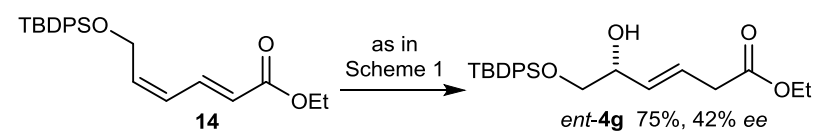

[24] D. A. Evans, J. A. Gauchet-Prunet, J. Org. Chem. 1993, 58, 24462453. 


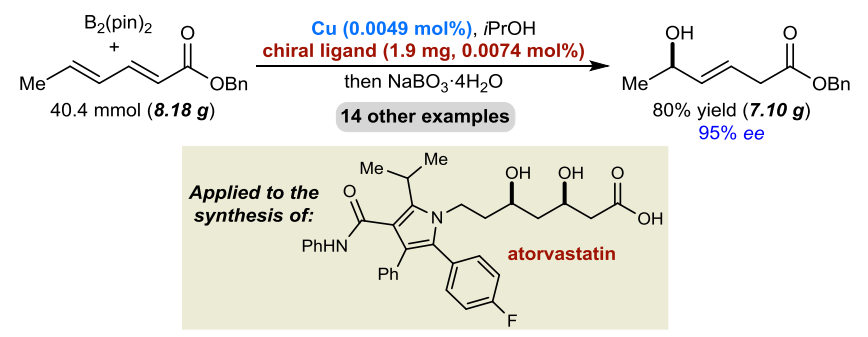

Allylboronates and Allylic Alcohols via Copper-Catalyzed 1,6-Boration

Yunfei Luo, lain D. Roy, Amaël G. E. Madec, Hon Wai Lam*

Page - Page

Enantioselective Synthesis of
Enantioselective copper-catalyzed 1,6borations of electron-deficient dienes with $\mathrm{B}_{2}(\text { pin })_{2}$ are described. The reactions proceed efficiently using catalyst loadings as low as 0.0049 mol\%, providing chiral allylboronates which, after oxidation, result in allylic alcohols in high enantioselectivities and
$1,6: 1,4$ ratios. Alternatively, the allylboronates can be used in stereoselective allylations of aldehydes. This process was also applied to a concise synthesis of atorvastatin, in which the key 1,6-boration was performed using only a $0.02 \mathrm{~mol} \%$ catalyst loading. 